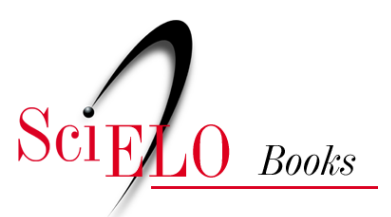

\title{
Redes sociais e circulação musical
}

\author{
Tatiana Rodrigues Lima
}

\section{SciELO Books / SciELO Livros / SciELO Libros}

LIMA, T.R. Redes sociais e circulação musical. In: RIBEIRO, J.C., FALCÃO, T., and SILVA, T. orgs. Midias sociais: saberes e representações [online]. Salvador: EDUFBA, 2012, pp. 197-215. ISBN 978-85-232-1734-1. Availablefrom: doi: 10.7476/9788523217341.011. Also available in ePUB from: http://books.scielo.org/id/hcmrr/epub/ribeiro-9788523217341.epub

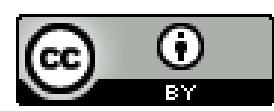

All the contents of this work, except where otherwise noted, is licensed under a Creative Commons Attribution $\underline{4.0 \text { International license. }}$

Todo o conteúdo deste trabalho, exceto quando houver ressalva, é publicado sob a licença Creative Commons Atribição 4.0.

Todo el contenido de esta obra, excepto donde se indique lo contrario, está bajo licencia de la licencia Creative Commons Reconocimento 4.0. 


\title{
Redes sociais e circulação musical
}

\author{
Tatiana Rodrigues Lima
}

Introdução

As formas de produzir, difundir e escutar música vêm passando por transformaçôes significativas na contemporaneidade devido às mudanças propiciadas pela digitalização da cadeia musical. A projeção obtida pela jovem compositora e intérprete brasileira Mallu Magalhães, após disponibilizar quatro canções em um perfil musical na rede social $M_{\text {SSpace }}{ }^{1}$ e ter em sua página 1,9 milhão de visitas em menos de seis meses (dados de 2007), é um exemplo dos trânsitos da música nas fronteiras entre o consumo de nicho e massivo, mediante o uso de plataformas digitais. (LIMA, 2011, p. 77) Entretanto, o cenário atual não pode ser abordado apenas pela ótica da ruptura. É preciso levar em conta as permanências e adaptações de práticas anteriores à circulação digital da música nas redes telemáticas e suas implicações no âmbito comunicacional.

1 Disponível em: <http://www.myspace.com/mallumagalhaes>. Criada em: 11/06/2007. Acesso em: 07/03/2010, quando o total de reproduções das canções disponibilizadas pela artista somava 3.488.192. A título de exemplo, no dia de acesso, o perfil de Magalhães contabilizava pouco mais do dobro de reproduções acumuladas até então no perfil de Paul MacCartney (Disponível em: $<$ http://www.myspace.com/paulmccartney>), criado em 09/04/2005, que somava 1.577 .769 reproduções. 
A utilização de redes sociais e outras plataformas por músicos estreantes, que gravam suas produções em home studios ${ }^{2}$ e se valem das redes telemáticas para difundi-las, não implica necessariamente na circunscrição dessa produção entre os usuários das plataformas. Por outro lado, a presença nas redes sociais não garante ao músico independente uma visibilidade nos moldes do caso citado. São encontrados, nas mesmas redes, perfis de músicos independentes e/ou estreantes e de estrelas do mainstream ${ }^{3}$ com repercussão bastante variada.

O compositor Leoni recomenda, em seu Manual de Sobrevivência na Internet (2010), que as redes sociais sejam usadas em paralelo ao desenvolvimento de home pages e blogs pelos músicos, como uma das formas de estabelecer um contato constante com os ouvintes.

Com tantas formas de se marcar presença no 'universo virtual', como MySpace, Orkut, Facebook, Twitter, BandCamp, ReverbNation, Blogs, Fotologs, LastFM, por que diabos alguém precisa de um espaço seu na web? Primeiro, porque é seu. Qualquer site, por maior e mais famoso que seja, pode fechar, sair de moda, parar de aceitar gente do Brasil, parar de ser gratuito, ser processado, sumir etc. (LEONI, 2010, p. 33-34)

Como ponto de partida para a discussão sobre as redes sociais e a circulação musical, serão narrados aqui alguns fatos da trajetória musical de Mallu Magalhães. Destaco apenas os acontecimentos que

2 Os home studios são estúdios de gravação surgidos em meados dos anos 1980, ancorados na tecnologia MIDI (Musical Instrument Digital Interface), criada em 1983. O MIDI é um protocolo, envolvendo hardware e programas (softwares), que permite a simulação digital de um estúdio, envolvendo gravadores multicanais, mesa de mixagem e processadores de sinais. $\mathrm{O}$ MIDI possibilitou a conexão em rede entre baterias eletrônicas, samplers, sintetizadores digitais e computadores. (THÉBERGE, 2006, p. 36) O sistema barateou os custos de gravação, uma vez que a produção musical passava a ocorrer sem os grandes investimentos anteriormente custeados majoritariamente pelas gravadoras.

3 Refiro-me ao mainstream como "sistema de produção/circulação das grandes companhias". (CARDOSO FILHO; JANOTTI JR, 2006, p. 18) 
ancoram as reflexões em torno do tema central deste artigo. ${ }^{4}$ Em seguida, são abordadas as experiências do compositor Leoni, que tem uma trajetória anterior à digitalização da circulação musical, a fim de extrair das situações abordadas inferências que permitam refletir sobre a cultura musical contemporânea.

\section{Mallu Magalhães: das redes sociais ao circuito convencional}

O lançamento musical de Mallu Magalhães ocorreu de uma forma não planejada. Quando completou 15 anos, em 2007, ela recebeu como presente de aniversário dos pais $\mathrm{R} \$ 1,5$ mil e usou a quantia na gravação de quatro canções de sua autoria com letras em inglês Tchubaruba, Don't You Leave Me, J1 e Get to Denmark - num pequeno estúdio, o Lúcia no Céu, em São Paulo, que oferecia serviços de gravação de CDs, demos e registros ao vivo.

A compositora colocou as gravações em um perfil musical no MySpace, ${ }^{5}$ no qual classifica sua produção como vinculada ao gênero folk music. Criada em 2003, nos EUA, a rede social ganhou versão em português justamente em 2007 e promoveu o perfil da cantora e compositora internamente, em banner exibido em espaços reservados para publicidade de suas páginas. $\mathrm{O}$ perfil da cantora começou a ter um boom de acessos e logo em seguida ela fez sua estreia nos palcos, em janeiro de 2008, realizando um show de abertura em uma apresentação do grupo mato-grossense Vanguart, em São Paulo. Por conta

\footnotetext{
4 A pesquisa em torno da emergência musical de Mallu Magalhães teve uma primeira abordagem, incluindo aspectos da configuração sonora de sua produção, no artigo Mallu Magalhães e as novas formas de circulação da música (LIMA, 2011, p. 76-90), do qual são extraídos elementos para a discussão sobre sua relação com as redes sociais.

5 Pelo fato de a abertura do perfil ter ocorrido em 2007 e a pesquisa que resulta neste artigo ter se iniciado em 2009, não é possível discutir os aspectos plásticos da página de Mallu Magalhães na época da divulgação das faixas, uma vez que o conteúdo e o design da página sofreram alterações.
} 
da presença de alguns jornalistas pautados para cobrir o grupo, Mallu Magalhães "ganhou destaque nos principais jornais, revistas e sites noticiosos do país". ${ }^{6}$ (ANTENORE, 2008, p. 73) A partir de então ela ingressou no circuito de festivais de música independente, apresentando-se no Jambolada, Eletronika, MADA, Coquetel Molotov, Gig Rock e em um festival de cunho mais comercial, o Planeta Terra.

Cinco gravadoras propuseram lançar um álbum de estreia de Mallu: as transnacionais Warner, EMI, Sony-BMG, Universal e o selo independente brasileiro Deckdisc, mas ela recusou as propostas. (ANTENORE, 2008, p. 78) Produziu um CD de forma independente, editou as composições pelo selo Agência de Música e fechou acordo com a operadora de telefonia móvel Vivo, para disponibilizar as faixas do álbum, intitulado Mallu Magalhães, para os usuários do sistema. Conforme matéria do jornal Folha de S. Paulo, de 20/10/2008:

[...] a cantora lançou seu primeiro disco em uma ação de marketing com uma operadora de celular, que está vendendo cada faixa por R \$ 1,99 em seu site. Além disso, cinco modelos de telefone estão sendo lançados com o álbum completo armazenado na memória. Em novembro, o CD chega às lojas. (CASTRO, 2008) $)^{7}$

Vale atentar que mesmo após viabilizar a comercialização de seus fonogramas no site da operadora, a compositora se valeu de um produto tradicional, o álbum em CD, como forma de circulação. No mesmo período, a Vivo utilizou a canção $J 1$ como trilha sonora de um comercial de telefones celulares pré-pagos veiculado na televisão aberta e por assinatura. Em seguida, Mallu Magalhães produziu um DVD

6 Alguns exemplos: entrevista na Trip publicada em 05 de março de 2008 [Disponível em: <http:// revistatrip.uol. com.br/revista/salada/peso-leve.html>. Acesso em: 23 maio 2010.]; matéria na edição de março da versão brasileira da revista mensal RollingStone [Disponível em: <http://www. rollingstone.com.br/ edicoes/18/textos/1966/>. Acesso em: 23 maio 2010]; além de capas dos segundos cadernos do Jornal do Brasil e Folha de S. Paulo, entre outras publicaçôes.

7 Notícia disponível em: <http://www1.folha.uol.com.br/folha/ilustrada/ult90u458008.shtml>. Acesso em: 07 jun. 2010. 
em suporte físico, lançado pelo mesmo selo independente, Agência de Música, que havia lançado seu CD (ANTENORE, 2008), em mais uma adoção de um formato de circulação convencional. Já no segundo CD, de 2009, que igualmente leva seu nome, a compositora vinculou-se formalmente a uma grande empresa da indústria fonográfica tradicional, a Sony Music, mas manteve a parceria com a Agência de Música.

Voltando ao momento de emergência de Mallu Magalhães, entre 2007 e 2008, convém ressaltar que houve uma diferença entre a produção musical disponibilizada pela cantora em seu perfil no MySpace e aquela que passou a circular nas plataformas da Vivo e em CD. Embora a cantora tenha passado a tocar com os músicos do estúdio Lúcia no Céu ${ }^{8}$ em shows ao vivo, as versões de Tchubaruba, J1 e Get to Denmark comercializadas no site da Vivo e em disco ${ }^{9}$ têm um padrão de qualidade superior à das disponibilizadas no MySpace. Percebe-se uma produção rebuscada em termos de arranjo, com maior exploração da dinâmica e interação entre instrumentos; na forma como soam os instrumentos (volumes em que são mixados, timbres e usos de efeitos), entre outros elementos.

Apesar de não ter estabelecido um vínculo com uma gravadora convencional, a compositora investiu em qualidade de configuração sonora no momento de diversificar sua circulação. Mas se por um lado a segunda produção apresenta maior apuro técnico, por outro, não há uma mudança radical de repertório visando a aceitação massiva, uma vez que as três composições de autoria de Mallu Magalhães migraram do perfil do MySpace para o site de vendas da Vivo, para os aparelhos celulares e para o CD da compositora.

8 Kadu Abecassis (guitarra), Jorge Moreira (bateria), Thiago Consorti (baixo) e Rodrigo de Alencar (piano).

9 As faixas foram gravadas e mixadas no AR Studios, do Rio de Janeiro, com produção de Mario Caldato Jr., e masterizadas em Los Angeles por Bernie Grundman. 
Em Nuevas tecnologias, música y experiencia, George Yúdice afirma que conquistar a preferência das massas não é pré-requisito para a circulação musical contemporânea.

$\mathrm{Na}$ 'época da reprodução digital', das redes que se valem dela e dos mercados de nicho que se abrem a partir dela, é questionável o uso da noção de 'massa' [...] As novas tecnologias afetaram a maneira como a música incide na organização social, desde os tradicionais clubes de melômanos a blogs, chats e sites de Internet, nos quais gostos musicais são um componente crucial nos perfis que atraem as pessoas a se relacionarem com seus congêneres, os quais podem viver à distância de dobrar uma esquina ou a vinte mil quilômetros, do outro lado do mundo. ${ }^{10}$ (YÚDICE, 2007, p. 22-23, tradução nossa)

A observação chama atenção para o fato de que, no ambiente contemporâneo, as músicas midiáticas não consumidas massivamente encontram formas de sustentabilidade de grande interesse do ponto de vista da comunicação. ${ }^{11}$ Mediante o aparato tecnológico digital, as gravações em variados formatos e suportes, materiais ou virtuais, dispóem de um amplo leque de possibilidades de circular, de forma que podem ir ao encontro do seu público com mais facilidade do que no período anterior à digitalização.

Isso ocorreu com as faixas disponibilizadas inicialmente por Mallu Magalhães no seu perfil do MySpace. A difusão inicial aconteceu através das ações de ouvintes-navegadores, em plataformas da internet,

10 Do original em espanhol: "En la 'época de la reproducción digital', de las redes que se valen de ella y los mercados de nicho que se abren a partir de ella, es cuestionable el uso de la noción de 'masa' [...] Las muevas tecnologías han afectado a la manera en que la música incide en la organización social, desde los tradicionales clubes de melómanos a los blogs, chats y sitios en Internet en los que los gustos musicales son un componente crucial de los perfiles que atraen a la gente a relacionarse con sus congéneres, los cuales pueden vivir a la vuelta de la esquina o a veinte mil kilómetros al otro lado del mundo".

11 A recente fragmentação do consumo proporcionada pela digitalização da música e sua circulação em redes telemáticas é tema de estudos tanto da área comunicacional quanto em perspectivas ligadas à economia e ao marketing, a exemplo da teoria da cauda longa. (ANDERSON, 2006) 
os quais indicaram e recomendaram as canções, constituindo-se nos primeiros críticos e divulgadores das composições. A aceitação inicial obtida pela cantora no MySpace foi certamente um dos fatores que fizeram a operadora de telefonia decidir vincular sua marca à produção da compositora. O talento, a criatividade (neste caso, a criação musical), o êxito em um dispositivo de comunicação surgido recentemente e a juventude como indicadora de perspectivas de mudanças e inovações estão em consonância com a valorização da tecnologia de ponta, que é um dos pilares do marketing da telefonia móvel. Ao veicular a música da cantora tanto no VT publicitário quanto em seu site e telefones celulares, a Vivo associa sua marca à autenticidade sugerida pelo percurso independente da adolescente que se projetou sem um aparato de divulgação massivo. O caso de Mallu Magalhães pode ser tomado como exemplo da progressiva perda de poder de triagem das gravadoras e demais instâncias de circulação convencional, como rádios e lojas físicas, na cultura musical, permitindo inferir que a música midiática produzida com pretensões de conquistar ouvintes de nicho é potencialmente massiva.

Segundo Janotti Jr. e Nogueira, após a popularização da internet, "parte do trabalho crítico se aproxima do trabalho de filtragem da informação executado por blogueiros e até mesmo por ferramentas de recomendação presentes nas plataformas de disponibilização de conteúdo musical”. (2010) Uma vez ingressando nas plataformas de circulação digital, o interesse de um grande número de ouvintes, mediante esquemas de divulgação paralelos ao da indústria musical, como a recomendação de fãs em e-mails pontuais, redes sociais, listas de discussão, blogs etc., ${ }^{12}$ pode levar ao ingresso posterior em formas massivas de divulgação. Mas como atrair a atenção do ouvinte diante

12 Evidentemente, grande parte da música midiática produzida fora da indústria fonográfica convencional não obtém visibilidade massiva, mas a autossustentação e a sucessão de lançamentos gera uma divulgação cumulativa. 
da profusão de oferta de arquivos sonoros nas redes sociais e outras plataformas digitais?

O compositor, instrumentista e cantor Leoni problematiza a eficácia das estratégias musicais ancoradas apenas em redes sociais como o MySpace e o Twitter:

[...] muita gente deixa recados no meu MySpace ou no meu Twitter com a seguinte mensagem: conheça nosso som. É claro que eles têm muito interesse em que as pessoas conheçam seu trabalho, mas eles ainda não me deram um motivo para que eu me interesse. No meio de uma infestação de bandas se divulgando na rede, disputando a minha atenção, porque eu iria escolher exatamente aquela para dar meu tempo? Não é à toa que essas mensagens dão muito pouco resultado. Eu tenho que ser instigado, provocado ou premiado para sair da minha inércia. (LEONI, 2010, p. 14)

No caso de Mallu Magalhães, vale notar que dois fatores influenciaram positivamente para seu êxito no MySpace. A rede social ancorada na música havia aberto uma representação no Brasil e tinha intenção de ampliar sua receita (captação de publicidade local), os acessos (views) de brasileiros e o número de perfis criados no País, o que implicava em destacar mais o conteúdo produzido por músicos locais, a fim de atrair o público-alvo. A compositora, por sua vez, tinha relações de proximidade com pessoas ligadas à representação brasileira da plataforma, o que facilitou a sua inclusão entre os perfis destacados. ${ }^{13}$

Como esse contexto favorável não é uma regra, e sim uma situação ocasional, Leoni defende uma presença ativa do músico nas redes, no

13 A informação sobre o banner foi obtida durante reunião do grupo de pesquisa Audiosfera. A representação do MySpace no Brasil foi fechada em 2009, quando a News Corporation, proprietária da plataforma, determinou a centralização das atividades de captação de publicidade no Brasil pelo escritório nacional de outra empresa de sua propriedade, a Fox. Em função disso, não foi possível obter mais detalhes sobre a decisão de promover o perfil de Mallu em banners do MySpace. 
sentido de fomentar a convergência entre perfis variados. Tal proposta é delineada a partir do relato do músico sobre suas experiências, abordado a seguir.

\section{Leoni: do circuito convencional às redes sociais}

Foi a partir da rede social Orkut, então muito popular no Brasil, que o músico Leoni passou a se interessar pelas plataformas digitais, em 2006. No início dos anos 1980 ele integrou a formação inicial da banda Kid Abelha e os Abóboras Selvagens. Em 1986 deixou o grupo e montou uma nova banda, Heróis da Resistência. Em 1993 partiu para uma carreira solo, teve composições gravadas por outros músicos e bandas e experimentou momentos de atuação intensa, alternados por fases de pouca repercussão musical. ${ }^{14}$

A história do meu site começou no Orkut. [...] descobri que havia uma comunidade de umas 40 pessoas que, de vez em quando, trocavam ideias sobre o meu trabalho [...]. Entrei na comunidade e isso bastou para dar um novo ânimo àquelas pessoas. Junto com o lançamento de dois discos de muito sucesso, que aumentaram muito a minha visibilidade no mundo real, houve um boom do Orkut no Brasil e logo minha comunidade chegava aos mil cadastrados. Além de outras comunidades específicas - fãs de uma determinada cidade ou de uma canção em especial - começarem a aparecer. Daí para 5.000, depois 10.000, tudo em velocidade cada vez maior. Cheguei a passar horas dos meus dias aceitando amigos e convidando-os para a minha comunidade. Um trabalho maçante e exaustivo, mas que deu ótimos resultados a longo prazo. Quando eu resolvi criar meu site, usei a forma de nos comunicarmos no Orkut, através de Fóruns, para ser a base do site. Nessa oportunidade a comunidade principal já tinha mais de 45.000 membros e

14 Compilação de informações do site oficial do músico. Disponível em: <http://www.leoni. com.br/ biografi a.php>. Acesso em: 12 ago. 2011 
havia mais de 150 outras sub-comunidades - até duas de 'Eu odeio o Leoni'! (LEONI, 2010, p. 25-26)

O músico experimentou diversas plataformas digitais e decidiu redigir um manual para "ajudar as bandas novas e alguns artistas mais rodados que estão perdidos na rede" (2010, p. 10). No texto, que saiu originalmente como e-book e depois foi publicado em meio impresso, Leoni faz algumas consideraçóes sobre as redes sociais. Ele defende a convergência entre o uso dessas redes e de plataformas próprias, como comentado acima, tomando por base sua atuação:

Na minha experiência, o MySpace virou um site basicamente de músicos. Claro que alguns artistas têm muitos fắs ali, mas no Brasil parece que você fica falando com seus pares. [...] O MySpace tem uma vantagem que pode acabar se voltando contra você. Como ele é totalmente personalizável - ao contrário do Orkut -, se o usuário não tiver um profissional para orientá-lo, é provável que termine com uma página muito confusa visualmente. Além disso, por conta dessa facilidade, muita gente acaba usando-o como se fosse seu próprio site, evitando custos. Junto com a aparência confusa traz, para quem age assim, uma imagem pouco profissional e 'barata'. (2010, p. 27)

Vale lembrar que também Mallu Magalhães utilizou o MySpace antes de publicar seu próprio site. A reação positiva ao conteúdo do perfil foi o que a fez investir em outras plataformas na internet. Em movimento semelhante, porém tendo uma carreira anterior de lançamentos fora do mundo virtual, Leoni igualmente passou a explorar as plataformas digitais e a aderir a novas redes além do Orkut. O músico usa atualmente o Facebook ${ }^{15}$ e o Twitter. ${ }^{16}$ Sobre esse último, faz algumas consideraçôes no seu livro:

\footnotetext{
15 Disponível em: < http://www.facebook.com/LeoniOficial>. Acesso em: 14 ago. 2011.

16 Disponível em: <https://twitter.com/\#!/Leoni_a_jato>. Acesso em: 11 ago. 2011.
} 
[...] eu tenho usado o Twitter para me informar sobre música, tecnologia e meio-ambiente, seguindo pessoas que escrevem sobre esses assuntos e que avisam quando postaram novos textos ou vídeos e, também, para informar meu público sobre o que eu estou fazendo profissionalmente - mandar fotos tiradas no camarim logo antes do show, avisar de uma promoção relâmpago, fazer enquetes instantâneas e avisar sobre novidades no meu site. (2010, p. 29)

Com base no depoimento, é possível perceber que o músico emprega o microblog Twitter para ações tangenciais à produção musical propriamente dita. As fotos de bastidores fomentam o interesse dos ouvintes sobre a atividade do músico para além da gravação, sobre sua rotina de produção. Já os avisos remetem os seguidores a conteúdos publicados em outras plataformas e as enquetes incentivam o diálogo entre músico e consumidor.

Infere-se que, para obter visibilidade e audibilidade, o músico contemporâneo passa a ser também o administrador ou o objeto de uma infinidade de textos e conteúdos desdobrados a partir da produção sonora, que envolvem a publicação, em diversas plataformas, de conteúdos audiovisuais (gráficos e vídeos), bem como a interação mais intensa com os fãs mediante o uso de redes sociais, sites e fóruns. A música é o ponto de partida para produtos derivados que exigem do autor ou de sua equipe habilidades e competências multimidiáticas e interativas. Como observa Yochai Benkler, em artigo sobre modelos de pagamento voluntário na internet, “é importante reconhecer que simplesmente colocar um site estático com uma opção de pagamento não é do que se trata a prática em questão". ${ }^{17}$ (BENKLER, 2011, p. 30, tradução nossa). O autor descreve uma série de ações e posturas já praticadas por músicos contemporâneos, a saber:

17 "it is important to recognize that simply putting a static website up with a payment option is not what the practice is about." 
- "Comunicação com os fãs: [...] No nível mínimo, inclui blogar e tuitar para os făs";

- "Comunicação entre os fãs: criando uma comunidade": mediante a utilização de plataformas que permitam a criação de fóruns, chats, listas de discussão etc.;

- "Colaboração com os fâs na música, em performances ou financiamento": o autor dá como exemplo trabalhos em que os fấs são convidados a colaborar participando de uma pré-venda ou cedendo, via upload, samplers de áudio por eles criados, sugestōes de letras de canções, fotografias e vídeos a serem incorporados ao projeto;

- "Provocando uma dinâmica de reciprocidade", que se materializa, por exemplo, nos "sistemas de pagamento voluntário", quando é facultado aos fâs remunerar ou não pelo conteúdo musical, bem como estabelecer o valor do pagamento;

- "Mudando o tom moral da conversa", com essa recomendação, Benkler sugere que, em vez de criminalizar os consumidores de música gratuita não-autorizados, como fez a indústria fonográfica, o músico deve informar aos que já baixaram seu material gratuitamente que, se eles gostaram do conteúdo, têm a possibilidade de remunerá-lo, indicando ainda as formas de obter os fonogramas legalmente. ${ }^{18}$ (BENKLER, 2011, p. 30, grifos do autor, tradução nossa)

Às competências multimidiáticas e interativas demandadas ao músico contemporâneo soma-se a necessidade de experimentar, acompa-

18 Os trechos citados em sequência têm as seguintes redaçôes em inglês: "Communication to fans: [...] At a minimal level, this includes blogging and tweeting to fans"; "Communication among fans: building a community"; "Collaboration with fans on music, performances, or funding:"; "Triggering reciprocity dynamics:"; "Changing the moral tone of the conversation". 
nhar e avaliar criticamente o processo de divulgação em plataformas digitais. Ao utilizar o Twitter, Leoni (2010, p. 29-30) observou que

[...] o efeito de um tweet sobre as pessoas não dura mais de meia hora, se durar tanto. Portanto, em algumas situações, é necessário repetir um post mais vezes para se ter certeza de que ele chegou a todos que poderiam se interessar por ele. Um teste que eu fiz foi o de dar uma canção através do bln.kr no Twitter. No momento em que eu avisava sobre a promoção a contagem de downloads disparava. Depois de meia-hora, o movimento já tinha reduzido muito e, uma hora depois, o contador parava totalmente. Repeti a operação a cada 4 horas e o resultado foi o mesmo. Parei de avisar e nunca mais houve um único download. No meu site o resultado é muito mais lento, mas muito mais duradouro, as pessoas continuam baixando as cançōes meses depois de terem sido lançadas.

O músico defende que "redes de relacionamento devem ser usadas para trocas e para atrair pessoas para o seu site. São uma passagem, não um destino" (2010, p. 30). Mas a experiência de Leoni, que era objeto de uma comunidade no Orkut antes mesmo de acessar a rede social, mostra que, independentemente de ter papel ativo nessas plataformas, o músico pode ter sua produção divulgada por ouvintes em comunidades e perfis. As informações sobre preferências musicais são sempre acionadas nas constituiçôes de perfis individuais em diversas redes sociais. Através da publicação de suas experiências e afinidades musicais, o ouvinte busca a atenção de seus pares. Ao tempo em que afirma um traço identitário, almeja atingir, mediante as redes telemáticas, aqueles que partilham do mesmo gosto e afetos. E as redes sociais e plataformas de publicação correspondem a esse desejo quando possibilitam a inserção de comentários e novos conteúdos por parte dos visitantes. Por outro lado, quando o músico passa a atuar nessas redes e comunidades, há um aumento do interesse e da adesão a essas páginas por parte do ouvinte. 


\section{Das experiências de Mallu Magalhães e Leoni ao cenário musical contemporâneo}

Se o consumo em mercados considerados de nicho confere a uma parcela da música contemporânea o status de não-massiva, ${ }^{19}$ os canais em que essa música circula envolvem as mesmas tecnologias que servem aos consumidores da música massiva. ${ }^{20} \mathrm{O}$ uso de tecnologias potencialmente massivas faz com que as delimitaçóes entre o que se pode chamar de "música de massas" e "música de nicho" sejam bastante instáveis. Produçôes musicais sem vínculos com gravadoras, como a de Mallu Magalhães, têm encontrado nas redes sociais e demais plataformas digitais um espaço para ampliar seu público, aumentando progressivamente a independência das antigas esferas que ocupavam posições centrais na circulação da música - gravadoras, rádios convencionais, lojas físicas, grande imprensa, mídias massivas de entretenimento etc. Práticas que começaram com o barateamento da produção musical - a digitalização das gravações e o lançamento de álbuns por selos independentes - encontraram na digitalização da circulação sonora maiores possibilidades de autossustentação. Já os músicos oriundos do circuito massivo tradicional, como Leoni, en-

19 Em artigo sobre Cidade e mobilidade. Telefones celulares, funçôes pós-massivas e territórios informacionais, André Lemos sugere observar a "relação estreita entre mídias com funções massivas (as 'clássicas' como o impresso, o rádio e a TV), e as mídias digitais com novas funçôes [...] 'pósmassivas' (internet, e suas diversas ferramentas como blogs, wikis, podcasts, redes P2P, softwares sociais, e os telefones celulares com múltiplas funçôes)”. (LEMOS, 2009, p. 4-5, grifos do autor) Lemos afirma que as mídias de função pós-massiva "funcionam a partir de redes telemáticas onde qualquer um pode produzir informação, 'liberando' o pólo da emissão, sem necessariamente haver empresas e conglomerados econômicos por trás. [...] O produto é personalizável e, na maioria das vezes, insiste em fluxos comunicacionais bi-direcionais (todos-todos), diferente do fluxo unidirecional (um-todos) das mídias de função massiva. (2009, p. 5-6)

20 Lemos compreende a função massiva como "um fluxo centralizado de informação, com o controle editorial do polo da emissão, por grandes empresas em processo de competição entre si, já que são financiadas pela publicidade. Busca-se, para manter as verbas publicitárias, sempre o hit, o sucesso de 'massa' [...] para pessoas que não se conhecem, que não estão juntas espacialmente e que assim têm pouca possibilidade de interagir”. (LEMOS, 2009, p. 5) 
contram nas redes sociais e demais plataformas novas oportunidades de divulgação e de interação com seus pares e com os ouvintes.

Desde os anos 1950 ocorrem fluxos entre produçóes independentes e indústria fonográfica, geralmente mediante parcerias entre selos e gravadoras de maior porte. Conforme Simon Frith (2006, p. 82), muitos produtos independentes chegavam aos escritórios das majors no momento da circulação e eram trabalhados pelos departamentos de marketing das grandes empresas. Mas cada vez com maior frequência, principalmente em função da popularização das redes telemáticas a partir dos anos 1990, as gravadoras têm sido dispensáveis à circulação da música underground. Atualmente, as plataformas digitais e redes sociais potencializaram as interações nas esferas de nicho.

São bandas que fazem sucesso graças a downloads na internet, sem terem lançado um único CD. São blogs antecipando tendências musicais antes das revistas especializadas. São versões sucessivas de videoclipes feitos por fâs. São redes sociais [...] que criam comunidades a partir da troca de arquivos sonoros pela internet. Sem falar nos estúdios caseiros, nos podcastings, no crescimento exponencial de gravadoras independentes e de vendas de música por unidade por meio da rede [...]. Tudo isso, em conjunto, chamando-nos a atenção para a revolução que a cibercultura introduziu no circuito de produção, circulação e consumo musical em pouco mais de uma década. (SÁ, 2009, p. 45)

O caso Mallu Magalhães traz o exemplo de uma produção independente que se valeu de formas de circulação alternativas tanto no modelo todos-todos, mediante seu perfil no MySpace, quanto no modelo um-todos, com a venda de suas canções no site e nos celulares da Vivo, o que ilustra os trânsitos da música pelas fronteiras do consumo de nicho e massivo. Mas não se pode ignorar que os sistemas de publicação e gerenciamento de conteúdo em redes telemáticas são utilizados atualmente tanto por artistas e fãs do mainstream quanto do underground, por isso os estudos envolvendo música e comunica- 
ção não devem considerar apenas a procedência dos suportes digitais utilizados.

Ao discutirem $O$ novo mainstream da música regional, Felipe Trotta e Márcio Monteiro (2008) chamam atenção, por exemplo, para gêneros gestados fora da indústria fonográfica convencional, como a axé music, o "brega" (sic), o reggae e o forró eletrônico, cujo êxito comercial ultrapassa "estética e quantitativamente os limites da classificação independente" (2008, p.1) em suas regiōes, transitando para o consumo nacional e até global. Embora estejam esteticamente atrelados à repetição de fórmulas de sucesso, como ocorre no mainstream, os gêneros estudados por Trotta e Monteiro emergiram fora da indústria fonográfica e obtiveram sucesso de público. Posteriormente, alguns se vincularam a gravadoras convencionais e passaram a circular em mídias massivas tradicionais. ${ }^{21}$

A classificação de uma produção musical nas categorias massiva, de nicho ou pós-massiva é, portanto, segura apenas em um determinado período de observação do texto e contexto musical. Afirmações definitivas são passíveis de questionamento, uma vez que as fronteiras entre essas instâncias são cada vez mais permeáveis. Carreiras musicais independentes podem ou não transitar por associações com setores ligados ao mainstream, pois, na contemporaneidade, música se tornou uma commodity empregada na configuração de inúmeros produtos, como ringtones; trilhas sonoras de games; propagandas; filmes e produtos televisivos; som ambiente de espaços públicos; além de ser conteúdo agregado a gadgets, como aparelhos celulares e outros equipamentos eletro-eletrônicos.

21 "Numa complexa engrenagem de produção musical articulada com canais de difusão radiofônica e uma intensa identificação regional baiana, a axé music se desloca do cenário circunscrito e 'independente' do carnaval de rua de Salvador para ocupar fatias significativas do mercado de música nacional, configurando-se como um dos três principais gêneros musicais do início da década de 1990.” (MONTEIRO; TROTTA, 2008, p. 6) 
Para entender a cultura musical contemporânea e o uso das redes sociais pelos músicos é preciso levar em conta que o novo cenário: (a) torna mais importante um contato direto entre músicos e ouvintes, uma vez que essa relação é potencializada mediante o uso da internet e de outras redes de comunicação, para além dos limites espaciais e de escala inerentes ao contato presencial. A revalorização do contato direto músico-ouvinte fica patente quando consideramos que os shows resistem enquanto reduto estável de receitas musicais mesmo em tempos de crise, mas (b) a conquista de futuras plateias ocorre, em grande parte, mediante a escuta de música, autorizada ou não, em plataformas das redes telemáticas, nas quais (c) o ouvinte é também um divulgador do trabalho de seus grupos e performers favoritos nas redes sociais e demais plataformas digitais, chegando a interferir nos produtos musicais ao realizar remixes, paródias e mashups, ou simples comentários em listas de discussão. Em toda a cadeia de produção, circulação e consumo musical, (d) há uma intensificação do emprego de tecnologias que tanto configuram produtos pautados nas novas sonoridades digitais quanto podem ser permeados pelo revival, acionando a memória de sonoridades elétricas e acústicas, bem como de repertórios do passado em produções simultaneamente novas e carregadas de referências históricas.

Com a crescente popularização do acesso à internet de banda larga, que otimiza a troca de arquivos de áudio e vídeo, estamos experimentando um momento de profusão de fonogramas antes impossível. É cada vez mais indispensável uma conexão entre a produção musical propriamente dita e as ações envolvendo disponibilização de vídeos e textos, bem como a ampliação da rede de contatos entre ouvintes e músicos. Do músico, não se espera que apenas componha e/ou execute música, além de marcar presença no rádio e TV divulgando seu trabalho. Os ouvintes o procuram no Twitter, Facebook e outras redes sociais, acompanham suas publicaçôes em blogs e sites, se apropriam da sua música em vídeos amadores e manipulações sonoras, como 
remixes e mashups, ou simplesmente incorporando seus fonogramas em páginas pessoais, redes sociais, ou disponibilizando suas gravações em sistemas p2p ou plataformas de compartilhamento.

\section{Referências}

ANDERSON, Chris. A Cauda Longa: do mercado de massa para o mercado de nicho. Trad. Afonso Celso da Cunha. Rio de Janeiro: Elsevier, 2006.

ANTENORE, Armando. Revolucionária aos 16 anos. Revista Bravo, n.134. São Paulo: Editora Abril S.A., out. 2008.

BENKLER, Yochai. Voluntary Payment Models. In: Rethinking Music: A Briefing Book. Boston, Massachusetts: The Berkman Center for Internet \& Society at Harvard University, 2011.

CARDOSO FILHO, Jorge; JANOTTI JR., Jeder Silveira. A música popular massiva, o mainstream e o underground: trajetórias e caminhos da música na cultura midiática. In: FREIRE FILHO, João; JANOTTI JR, Jeder (Org.). Comunicação \& música popular massiva. Salvador: Edufba, 2006, p. 11-24.

CASTRO, Letícia de. Aos 16, Mallu Magalhães estréia disco como adulta. Folha de S. Paulo, 20 de outubro de 2008. São Paulo: Empresa Folha da Manhã, 2008. Disponível em: <http://www1.folha. uol.com.br/folha/ilustrada/ult 90u458008. shtml>. Acesso em: 07 jun. 2010.

FRITH, Simon. La industria de la musica popular. In: FRITH, Simon; STRAW, Will; STREET, John (Org.). La outra historia del rock. Trad. Jorge Conde. Barcelona: Ediciones Robinbook, 2006. p. 53-86.

HEBDIGE, Dick. Subculture: the meaning of style. Londres: Routledge, 2002. JANOTTI JR., Jeder Silveira; NOGUEIRA, Bruno Pedrosa. Um museu de grandes novidades: crítica e jornalismo musical em tempos de internet. In: Encontro da Compós, 19, 2010, Rio de Janeiro. Anais... Rio de Janeiro: Compós, 2012. (Texto apresentado ao Grupo de Trabalho Mídia e Entretenimento).

LEMOS, André. Cidade e mobilidade. Telefones celulares, funções pós-massivas e territórios informacionais. Revista Intermídias, ano 5, n. 9. Praia de Carapebus, Serra-ES, 2009. Disponível em: <http://www.intermidias.com/txt/ed9/cidade\%20 e\%20mobilidade_andrelemos. pdf $>$. Acesso em: 15 nov. 2009. 
LEONI. Manual de sobrevivência no mundo digital. Rio de Janeiro: Editora Sinergia, 2010.

LIMA, Tatiana Rodrigues. Mallu Magalhães e as novas formas de circulação da música. Revista Animus, v. 10, n. 19, 2011. Santa Maria RS: 2011, p. 76-90. Disponível em: <http://cascavel. ufsm.br/revistas/ojs-2.2.2/index.php/animus/ article/viewFile/2984/2477>. Acesso em: 13 dez. 2011.

MONTEIRO, Márcio; TROTTA, Felipe. O novo mainstream da música regional: axé, brega, reggae e forró eletrônico no Nordeste. Revista E-compós, v. 11, n. 2. Brasília, maio/ago 2008, p. 1-15. Disponível em: <http://www.compos.org.br/seer/ index.php/ecompos /article/viewFile/295 /278>. Acesso em: 09 abr. 2010.

SÁ, Simone Pereira de. O CD morreu? Viva o Vinil!. In: PERPÉTUO, Irineu Franco; SILVEIRA, Sergio Amadeu (Org.). O futuro da música depois da morte do CD. São Paulo: Momento Editorial, 2009, p. 49-72.

THÉBERGE, Paul. 'Conectados': la tecnologia e la musica popular. In: FRITH, Simon; STRAW, Will; STREET, John (Org.). La outra historia del rock. Trad. Jorge Conde. Barcelona: Ediciones Robinbook, 2006, p. 25-52.

YÚDICE, George. Nuevas tecnologias, música y experiência. Barcelona: Gedisa, 2007. 